\title{
STEM Education and Nature: from Neurosciences to Nano Sciences
}

\author{
Hafedh Abdelmelek* and Amel Hanini \\ Faculty of Sciences, Carthage University, Tunisia \\ Received: September 15, 2017; Published: September 27, 2017 \\ *Corresponding author: Hafedh Abdelmelek, Laboratory of Physiologie Intégrée, Faculty of Sciences, Carthage University, Tunisia; \\ Tel: 21693006057; Fax: 216590566; Email: Hafedh.Abdelmelek@fsb.rnu.tn
}

\begin{abstract}
Parents and educators think that STEM education is a fully integrated methodology to teach all disciplines-Science, Technology, Engineering, and Mathematics. Although, such transdisciplinary STEM education is not enough we have to consider art, music and a hole life conditions. Multidisciplinary integration, in which neurosciences and nanosciences focus on curriculum organized around personal motivation of children. STEM education associated to art and literature makes learning more compatible with life and relevant by giving children opportunities to apply the skills and knowledge they have learned in a formal and /or informal methods.
\end{abstract}

Keywords : STEM; Nature; WIFI; Neurosciences; Nanosciences

\section{Mini Review}

We devote a lot of effort to promote STEM education and methods for our students and young children. During USA STEM program especially in San Antonio, Texas (The National Sciences Teachers Association: NSTA), we spoke with U.S. experts about what sparked our early interest in science, technology and engineering and how to inspire the next generation of STEM leaders. When we were growing up, our parents were not in STEM education. Later, when we started looking at colleges, we discovered that we have a keen interest in fields related to the sciences. Also, when we were in the elementary Tunisian school, we had friends who lacked toys and we spent a lot of time together trying to design such toys as cars, planes, boats... things like that.

To us it just seemed to make sense that there were so many things that hadn't changed about cars for so long that we could do it better at age 6 or 10. With our children, when we talked about STEM they asked us several questions about nanosciences, black holes, gravity and we spent a lot of time finding the right words to answer to all these questions. Based on these experiences with our and other children in our town, we decided to develop a children's municipal council and to work with before making decisions about the city, STEM education, environment and other topics. It made sense for us because we are preparing curricula, institutions, and a new environment for them. These youth communicate their feelings and ideas which are noted and appreciated by the municipal council and considered in the final decisions. In many villages in Tunisia, the landscape and its life style offers creativity and motivation to study science, which is confirmed by the great number of outstanding STEM students' living in these area like Metline at Bizerte (Tunisia).

As a Neuroscientist, we believe that constraints are very important for the building of knowledge and the improvement of our thinking. When you do design work, it's never straightforward we have to accept failure before success and we must focus on teaching concepts rather than passive knowledge in schools. Innovation almost approaches being art-like, an artistic kind of thing, where creativity and the way you think about the problem sometimes will yield a different design than someone would originally think. In our point of view art is linked with science and the virtual teaching (TechBook,). TechBook completes, STEM education but we have to prepare good teachers to teach a sound scientific approach to science based on their own real experiences. There were many ways to promote STEM education. The first is the actual teaching of nanosciences at a late stage. It just makes it easier to operate nanotechnology and understand the interaction between all the systems in the nature.

At that point we really understand a lot of information about how the systems work, what kinds of interfaces the different systems have and their interactions. Life adopts the bottom-up approach and it is very important to introduce nanosciences at the beginning of any courses in STEM education before teaching math, physics, or chemistry. The thing that excites us is we're finally at that stage where we can have an interaction of both human 
systems and machine systems. However, the question is whether this combination can lead really to STEM education improvement. At the end, we're going to need a lot of knowledgeable people in the next generation to help us to continue to push that forward. Although, we sit here and we're very worried about the short term-how do we get people who are qualified to do jobs in STEM education in Tunisia and in other countries: How are we going to make sure that we have the people to do that work in the near future in Tunisia, Europe, USA,..etc, or other countries at 2030? We think that the most important thing is to make it relevant. It was our most important target when we were young when the brain becomes more efficient and reactive by novelty and fail/success experiences.

Learning about how, for instance, life works was very interesting to me because we studied it every day. If you want to get kids interested and keep them interested in the STEM fields, you have to make it relevant and to give them a good environment. We really don't care what the answer about black holes or other universe questions frequently asked by children. When we was a child, we had a long time to think and observe plants and animals in our nature (especially rural area) and a very keen understanding of science at a very young age. We think parents need to discuss with their children about life science, nature, and the universe and to visit science museums. In elementary schools or high school, the quality of STEM education should be related to motivation, attention, perception of time and stress. Based on our expertise in the field of the evaluation of bioeffects of Electromagnetic Field EMF (Mobile phone, WIFI, electronic equipment [1-4], we ought to control the time of exposure of our children to EMF in order to reduce stress and to enhance memorization and thinking leading to a boost of STEM knowledge.

Our previous studies point to the probable change of behavior, attention, memorization when children are exposed for long time to EMF. In addition, we think that a lot of children don't get to see people working in STEM fields. It's a lot easier to picture yourself doing something that you've seen someone else do. It is when children are in school that boys and girls are starting to decide whether they like or whether they do not like science and math. STEM is important, it is absolutely critical that we do it well together with our kids. We try to stress all the time that we need to do it better; we need to be better at emphasizing the STEM disciplines throughout, but not at the expense of some of the other things that we teach. Although, we don't always use calculus every day in our Labs, we do use language every day. We think to develop multiethnic universities with a wonderful landscape to give children or student the time to think, to communicate and to observe nature. Nature has the entire STEM field that is why teaching nanosciences is primordial.

Nature functions with bottom-up approaches that use all scientific area without any compartmentalization (S/T/E/M): Biology, Physics, Chemistry, Computer sciences and Mathematics. We have to connect STEM education, entrepreneurship and economy. We would like to see reform in both student attitudes toward project-based-learning and professor's willingness and qualification to be teaching entrepreneurial processes at universities. We focus specifically to three different actors in education reform that need to coincide with each other: students, teachers, and systemic structure (curriculum, funding, and expectations). Student don't have much experience in working on innovative or creative projects (across all subject areas), and it's difficult to get them interested when they don't see others around them being proactive. The result is that students are then still "not serious about their ideas" when it comes to their final projects and graduation from the university; at a time when students should be encouraged to develop their entrepreneurial intentions. We are working to change the entrepreneurial environment for those in the STEM field in Tunisia, and we recommend for multiapproaches for attracting students to entrepreneurship and business creation. We hope to be able to aid students in their endeavors and help open new entrepreneurial opportunities in STEM fields.

\section{References}

1. Othman H, Ammari M, Rtibi K, Bensaid N, Sakly M, et al. (2017) Postnatal development and behavior effects of in-utero exposure of rats to radiofrequency waves emitted from conventional WiFi devices. Environ Toxicol Pharmacol 52: 239-247.

2. Othman H, Ammari M, Sakly M, Abdelmelek H (2017) Effects of repeated restraint stress and WiFi signal exposure on behavior and oxidative stress in rats. Metab Brain Dis

3. Othman H, Ammari M, Sakly M, Abdelmelek H (2017) Effects of prenatal exposure to WIFI signal $(2.45 \mathrm{GHz})$ on postnatal development and behavior in rat: Influence of maternal restraint. Behav Brain Res 326: 291-302.

4. Saili L, Hanini A, Smirani C, Azzouz I, Azzouz A, et al. (2015) Effects of acute exposure to WIFI signals $(2.45 \mathrm{GHz})$ on heart variability and blood pressure in Albinos rabbit. Environ Toxicol Pharmacol 40(2): 600-605.

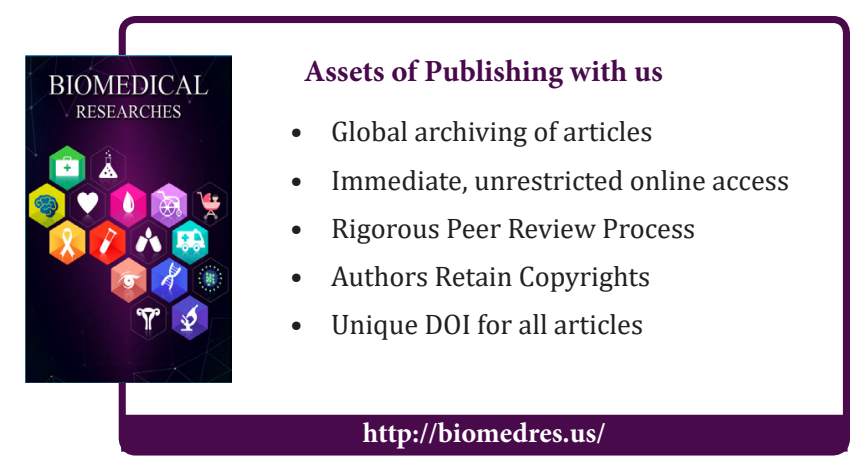

